\title{
Poster Presentation: A Self-Regulating Learning Tool for Undergraduate Dental Students
}

Talal H Salame*

Department of Oral Rehabilitation, Faculty of Dentistry, The University of Sydney

Received: February 15, 2021; Accepted: February 24, 2021; Published: March 07, 2021

${ }^{*}$ Corresponding author: Talal H Salame,Department of Oral Rehabilitation, Faculty of Dentistry, The University of Sydney; E-mail: talalsalame@ hotmail.com

\begin{abstract}
Poster templates have been widely used in presenting clinical information or research results in medical seminars and scientific conferences. Posters represent a simple, fast and straightforward way to present ideas, communicate accomplishments and evaluate progress and achievements. The use of interactive materials within the poster such as illustrations, graphs and maps makes it easy to be presented and understood. Posters could also be used as a teaching method in academic environment and have been commonly used as educational tool. Few attempts have been made to use this method as a self-learning tool by university students. This paper discusses an attempt to implement poster presentation as a self-regulating learning tool for undergraduate dental students, to help them develop their scholarly role and professional skills in innovative way.

Keywords: Poster Presentation; Learning Tools; Self-Learning; University Teaching; Teaching Methods; Teaching Techniques; Curriculum Innovation; Faculty Development; Dental Education; Contemporary Teaching.
\end{abstract}

\section{Introduction}

Poster presentation has been widely used by researchers to introduce research projects or to present research results at the end of a project; and also in the clinical field. However;poster presentation has shown to be an effective tool for university students in the process of learning[1-4]. It has been demonstrated that adding graphical illustrations; beside verbal representation of knowledge; will enhance the learning process and improve the quality of learning for students [5]. As an example; the use of multimedia that integrated verbal explanation with visual representation has shown to significantly improve the students understanding of scientific phenomenon; especially for those inexperienced learners [6]. In addition to the accumulation of knowledge that students couldreceive during preparing for their poster either by experimenting or by researching the literature; the processes of writing; designing and adding visual enhancement through pictures; images; graphs and tables will add an element of fun to their learning experience [7]. Other than acquiring scientific knowledge and improving presentation skills; poster presentation will improve other personal attributes to the studentcharacter such as confidence; self-esteem; creativity; professionalism and inter-professional interaction [1,2,4,8]. Poster presentation has shown to be a practical; reliable and valid tool in assessing the performance and progress of university students [9].

In a practice oriented profession;such as medicine and dentistry; more focus have been given to the practical side of the students education. In addition to medical knowledge and clinical expertise; development of parallel skills such as presenting information and communicating ideas becomes necessity in contemporary practice. In addition; the dental field showed to be going through immense progress within the last few decades; and there is an essential need for the present-day dentist to stay upto date by continuously acquiring and applying new knowledge. Training students to prepare and present posters as part of their undergraduate scholarly progress could be a reliable way to formulate future dentists for such a role in their practices.

\section{Poster Presentation as a Self-Learning Tool}

At the faculty of dentistry; university of Sydney; a trial was made in the Biomaterials Science Unit; to implement poster presentation as a new tool of self-regulating learning dental materials for first year dental students. Students were given a range of topics to research about the characteristics and properties of dental materials that are commonly used in the dental practice by various dental health professionals such as dentists; dental prosthetists and dental technicians. No prior knowledge about any of the materials in question was given to the students; they were asked to research about their specific materials in the literature; to setup their own experiments by referring to previous research in the same area; to test their hypothesis and to discuss their results through their poster presentation. Prior to commencement of the experimental phase the students were requested to email a 1 page outline of the protocol they intended to follow to address the topic question they were assigned. This was commented upon and responded to within a few days. The materials for the experiments were provided by the faculty; minimal equipment; such as digital callipers and where necessary curing lights; were also provided.Students were given access to the prosthesis laboratory to execute their experiments. 
The posters were supposed to include information about all steps of their projects starting with the literature review; hypothesis generation; methodology; results and finally discussion. A presentation day of two sessions was arranged in the faculty for all the 82 students. Each student was supposed to present for a duration of 10 minutes forthe entire group and a judging panel of 4 staff members from various departments. Each staff member and all the students were assessing the individual presentations using individual evaluation sheets. Evaluation criteria considered the topic; the poster appearance; the distribution of the information in the poster and the presentation itself. At a subsequent day; the students participated in a survey in the form of a short questionnaire to express their opinion about their new learning experience.

73 out of 82 students answered the survey. Students in general enjoyed the process and they were satisfied about the poster presentation as a learning tool. The opinion of 54 of them varied between useful; very useful or interesting new learning experience. According to them the experience helped them first to better understand various dental materials by experimenting their properties; and by presenting their projects; students were able to develop their presentation skills and their public speaking abilities. In addition; and by watching other students'presentations that were discussing different properties of similar materials;most of the students acknowledged that they were able to understand various properties of one material and discover new ways and methodological approach in experimenting. According to them; this gave them new insights in the world of research. Also the students found that interacting with tutors and other students through questions and answers during the presentation sessiongave them better understanding of their projects and different meaning to their results.

However; some students found this experience not totally satisfactory; but their criticism was more focused on the technical side of the process rather than on its content. This included lack of available materials to be used in their experiments; difficulties to find the proper literature review of some of the materials; the length of the presentation time; and the lack of knowledge and/ or expertise regarding this process. Interestingly; most of the students wished to have more frequent days like this with longer time for their presentation in future days; in order to better enhance their experience in researching for new information; and in presentation skills.

\section{Conclusion}

Poster presentation proved to be an enjoyable experience by first year dental students; especially for those who did not experiment this process in their previous studies. During the process of presenting their posters; the students could receive feedback from their peers and faculty members. This provided them the opportunity to teach and learn from each other; and to improve their communication and networking skills. This new experience helped them widening their horizon regarding the self-learning processes and taught them that different ways could be followed in their trip to seek knowledge. It also gave them and introduction to the world of research and helped them understand that clinical dentistry is not the only way to go in the future. Other thanthe knowledge that students could have acquired during the preparation of their posters; the process of researching; experimenting; writing and presenting armed them with skills and expertise that could reflect directly on their scholarly progress and professional development or to be used later in their life and personal growth.This experiment showed that poster presentation can be used effectively by graduate students to prepare and present information; to gather knowledge and to acquire and improve visual; written; and communication skills.

\section{References}

1. Mottet EA, Jones BL. The poster session: an overlooked management tool. J Nurs Adm. 1988;18(7-8):29-33.

2. Handron DS. Poster presentations: a tool for evaluating nursing students. Nurse Educ. 1994;19(1):17-19.

3. Rush K, Merritt-Gray M, Noel J. The poster assignment: a connected teaching strategy for increasing student comfort with issues of sexuality. Nurse Educ Today. 1995;15:298-302

4. Moneyham L, Ura D, Ellwood S, Bruno B. The Poster Presentation as an Educational Tool. Nurse Educ. 1994;21(4):45-47.

5. Verdi MP, Kulhavy RW. Learning with maps and texts: An overview. Educational Psychology Review. 2002;14(1):27-46.

6. Mayer RE. Multimedia Learning: Are We Asking the Right Questions? Educ Psychol. 1997;32(1):1-19.

7. Mellish JM, Brink H. Teaching and administration for nurses. Second edition. Durban: Butterworth publishers pty ltd. 1986.

8. McCann CA, Sramac RS, Rudy SJ. The poster exhibit: planning, development, andpresentation. Orthop Nurs. 1994;13(3):43-49.

9. Oliveira A. Poster presentation and learning log: alternatives inassessment at undergraduate and graduate levels. Signóticav. 2008;20(2):235-252. 